\title{
There's more to the economics of consumption than (almost) unconstrained utility maximisation
}

\author{
G. M. Peter Swann
}

This chapter was written in response to the presentation given at the CRIC workshop by Warde (Chapter 2 in this book). In summarising, Warde said that the main message of his paper was, perhaps, that there is more to the sociology of consumption than Thorstein Veblen. This is an important message, and relevant for two groups. First, to his fellow sociologists, that they should not be preoccupied with the exceptional and conspicuous forms of consumption. Second, to other social scientists - economists like this author, for example - that we should not form the wrong impression of where the sociology of consumption is going.

Moreover, it seems that it is of equal importance that this book should contain a chapter emphasising that there is more to the economics of consumption than the free choice and utility maximisation of 'modern' neoclassical consumer theory. Again this chapter should address two audiences: those mainstream economists who understand this message in principle, but still focus their energies on deriving ever more elaborate optimisation algorithms; and the other social scientists who still, mistakenly, believe that 'there $i s$ nothing more to the economics of consumption than utility maximisation'.

Between this introduction and the conclusion the chapter is divided into five sections. The first looks at the hard core of modern economics of consumption. In this, consumer behaviour is about utility maximisation - or, to be more precise, it is about an axiomatic theory of demand. If these axioms are accepted, then modern demand theory shows that the consumer behaves as if he or she were maximising an ordinal utility function. This ordinal function is very different from the cardinal utility function of Bentham. How can we characterise this modern theory? The theory is rigorous, certainly, and it has offered many professional economists the opportunity to demonstrate their technical bravura. But it is shallow in two senses: it seems to imply a very simplistic notion of how the consumer behaves but at the same time it actually contains very little empirical content.

The second section looks back at the writings on consumption by the 'giants' - the nineteenth and early twentieth-century pioneers of economics. 
Many of the 'giants' had a much richer conception of the consumer, even if none of them managed to develop such a sophisticated theory as that described in section one. Given these rich foundations, why did economics converge on analysing one very special (and perhaps implausible) view of consumption behaviour? The work of Marshall gives part of the answer. In his classic Principles of Economics (1920) Marshall gives a rich account of a consumer who exhibits many of the more subtle forms of consumer behaviour that interest us now. But Marshall was also determined to go beyond description and to develop a more rigorous theory, and he felt able to do that only for the (analytically) simplest, utility-maximising kinds of behaviour.

The third section turns to some of the 'travellers': post-war economists who have visited other disciplines and returned to take issue with the modern mainstream. Some have shown how economics would do well to learn from other social sciences - psychology, anthropology and sociology, and indeed from the business management disciplines (notably marketing). Others have argued that microeconomic theory based on utility-maximising consumers leads to a range of anomalies. Most prominent among these is a possible fallacy in the rationale of economic growth. As Galbraith (1958) argues, proponents of growth argue that economic growth is good because it satisfies consumer wants. But, he continues, if consumer wants are created by marketers - created, indeed, by those who want to sell economic growth then we should have serious doubts about the value of growth.

The fourth section looks at some of the relatively recent work in economics (the last twenty-five years or so) in which economists have started to take the subtleties of consumption behaviour more seriously. Many of these contributions draw heavily on the findings of other social sciences that have taken a more comprehensive view of consumption, even if these findings are not acknowledged explicitly. The contributions listed here are all ones in which attention to subtleties does not compromise the mainstream ideal of rigour. They indicate that mainstream economics is now taking consumption seriously, even if the core of demand theory still has a very strong hold.

The fifth and final section takes a brief look at the future. One of the most exciting developments of the last ten to fifteen years has been the increasing attention paid to dynamic increasing returns, or 'path dependence', in economic phenomena. This is a huge change from the traditional view of economic equilibrium. In the traditional view, the economic system has a state of grace to which it will converge, and any disturbances simply delay the achievement of that state. In economies with dynamic increasing returns, the final outcome of an economic process is not like this state of grace: indeed, the character of the outcome is dependent on all the disturbances that have taken place along the line. Such thinking has started to permeate economic analysis of consumption. One particularly interesting development is the application of agent-based modelling to the analysis of consumption - especially waves in consumption, or 'hits'. An intriguing prospect emerges from the convergence of virtual reality modelling and agent-based modelling of consumption. 


\section{The mainstream: rigour and revealed preference}

Let us start with the hard core of the modern mainstream economics of consumption. But remember - as noted above - that this is not to start at the beginning, chronologically speaking. The next section will revisit the work of the nineteenth- and early twentieth-century pioneers and asks why economics got stuck on the particular track described in this section.

Gorman (1976) recounts how Mary Douglas, after hearing an account of recent developments in the mainstream economic theory of consumption, said, 'Utility theory is empty, so we can fill it.' Some sociologists find this puzzling: is not utility theory based on many strong assumptions? Actually, Douglas's perspective is spot-on. Utility theory is based on a very small number of axioms. These may be strong and they may sometimes be unwarranted, but they are not many.

The core theory is as follows. The consumer is assumed to have a complete, transitive, reflexive preference ordering over all possible bundles of goods and services. Complete means that, for any pair of bundles $i$ and $j$, either $i$ is preferred to $j(i \mathrm{P} j)$, or $j$ is preferred to $i(j P i)$, or else the consumer is indifferent as between $i$ and $j(i I j)$. There are no instances where the consumer is incapable of ranking alternatives. Transitive means that if $i$ is preferred to $j(i P j)$, and $j$ is preferred to $k(j P k)$, then $i$ is preferred to $k(i P k)$. Reflexive means that $i$ is as good as itself, so that (iIi) - a seemingly trivial requirement, but a mathematical necessity. These are the three core axioms of utility theory, though, as Deaton and Muellbauer (1980, pp. 26-9) point out, they are generally supplemented by additional axioms of continuity, non-satiation and convexity.

If these axioms hold, then this preference ordering can be summarised by the function $u(x)$, which is defined over all possible bundles described by the vector $x$. Confusingly, perhaps, $u(x)$ is often called a 'utility' function, though its alternative name - the 'preference function' is perhaps more appropriate. So the modern 'utility' function - the object of much suspicion among other social scientists - does not rest on an elaborate Benthamite utilitarian calculus, but simply defines a preference ordering. Indeed, a very important property of this modern preference function is the fact that any other function $u^{*}(x)$ $=f\{u(x)\}$ where $f\{$.$\} is a continuous, monotonically increasing function, is$ also a perfectly good representation of the consumer's preferences. In simple terms this means that the preference function is simply an ordering: if the consumer's first, second and third choices from a particular set are (respectively) $a, b, c$, then this preferences ordering is conveyed equally well by the function $u(a)=3, u(b)=2, u(c)=1$ or by the function $u^{*}(a)=10, u^{*}(b)=$ $8, u^{*}(c)=3$.

As the important work of Gorman (1976), among others, went on to show, the economically interesting part of preferences can be defined by the dual cost functions which define the cost of reaching a certain value of $u$ as a function of prices (Deaton and Muellbauer, 1980). This is especially useful in the 
light of Shephard's lemma, which shows that the derivative of a cost function with respect to a particular price (say $i$ ) defines the demand function for product $i$. Strictly this is a Hicksian demand function - that is, it defines demand as a function of prices and real income.

This has been hugely important for the development of empirical studies of demand in mainstream economics. It meant that the empirical tradition of estimating demand functions from actual market data with the use of econometrics could be integrated with the mainstream theory of consumer demand. Setting aside the small matter of aggregation ${ }^{1}-$ that is, whether market demand functions can be interpreted as the demand function of a representative consumer - this gave a strong theoretical underpinning to common empirical practice.

In this neoclassical theory of consumption, stemming from Marshall (1920) and surveyed most comprehensively in Deaton and Muellbauer $(1980),{ }^{2}$ the consumer is an isolated optimiser. Choice is constrained maximisation, and while the constraints always bite, the consumer nevertheless has a large degree of discretion. Deaton and Muellbauer (1980) show how the theory can be extended to human capital and labour supply, durable goods, choice under uncertainty, consumer index numbers, household characteristics and household welfare comparisons, and social welfare and inequality. While the main focus of Deaton and Muellbauer is on circumstances in which consumers have a lot of choice, they also examine consumer behaviour under familial or life-cycle constraints.

Two of the classic econometric studies of consumer demand build on these foundations. Stone's (1954) study of consumer behaviour in the United Kingdom is one of the great works of applied econometrics. Throughout, he consistently uses economic theory to guide his applied econometric method. While subsequent studies have had access to better and more voluminous data and have refined the econometric techniques used, Stone's study makes major advances in estimating price and income elasticities for a wide variety of consumer goods. Equally, Houthakker and Taylor's (1970) study of consumption in the United States is another major econometric benchmark.

Empirical economists have for the most part had a strong preference for what is called the technique of revealed preference. The aim is to make inferences about preferences from observed market behaviour. Many sociologists, of course, would dispute whether observed behaviour does actually reveal much about preferences. As Warde makes clear (in Chapter 2 of this book), this is not a view with which sociologists have much sympathy. This difference in perspectives is beautifully summarised by Duesenberry: 'economics is all about choices, while sociology is about why people have no choices'. ${ }^{3}$ But let's park that issue for now, and return to it below. For now, let's focus on the economic mainstream on its own terms.

Why do economists prefer revealed preference as a technique? Why do economists still make relatively little use of the stated preference methods used in marketing, and elsewhere? There are several reasons for this, and 
there is not space to cover them all here. But the two most important are probably these.

First, applied economists have traditionally been sceptical of explanations offered by consumers (or businessmen, for that matter). Typically economists believe that if a consumer (or other actor) is asked to account for his behaviour he will give a distorted response. The reasons for distortion are twofold. There may be randomness: if asked how they would respond to a particular stimulus, the respondent may just give an unreliable answer. A hypothetical question yields a hypothetical answer. Probably more serious, the respondent may deliberately adjust his answer, as the following example suggests. Suppose a consumer is surveyed about his attitude to rail services, and it is clear that (part of) the purpose of the survey is to explore the scope to increase fares. Then it is reasonable to expect that many respondents will modify their answers to imply that demand exhibits a sensitivity to price, which in reality it may not. Respondents do this in the hope that such responses will deter the rail operator from raising prices. This issue of respondent bias has been studied in the literature. Marketers are usually aware of it, but consider that the biases arising from it may be less serious that the difficulties encountered in the indirect inference required in revealed preference analysis - see below.

The second reason why economists are sceptical about consumer 'accounts' lies much deeper in the fundamental methodological character of economics. To understand this we need to take a little detour. In 1933 the Econometric Society was founded - a society that has been hugely influential on the subsequent evolution of economics, so much so that that Popper (1957, p. 60 n.) for one considered that economics went through a 'Newtonian revolution'. The Econometric Society's founding fathers believed that the future of economics as a science lay with the application of mathematical and statistical methods to economic theory and applied economics. ${ }^{4}$ In particular, the applied programme would apply statistical techniques of indirect inference to market data. Other 'softer' methods, including case studies and historical methods, became less prominent as statistical analysis became more prominent.

Not all economists thought the research programme of the Econometric Society was a good thing. Keynes (1939), for one, famously described econometrics as a 'brand of statistical alchemy'. Indeed, one of the most influential founding fathers, Ragnar Frisch, who shared the first Nobel Prize in Economics in 1969 , had by the late 1950 s come to the view that econometric techniques alone would not unlock the relationships of economics. (The evolution of his thinking on this matter is summarised in Swann, 1989.)

The purpose of taking this detour is not to assess the success or otherwise of the Econometric Society experiment. Rather, it is to describe the setting in which revealed preference became the preferred empirical approach to analysing questions of consumption. Revealed preference required methodologies that are consistent with the Econometric Society vision: stated preference and ethnographic work did not. 
Revealed preference is, however, a problematic technique, for at least three reasons. First, as noted above, it is based on the assumption that consumption behaviour reveals something about preferences - an assumption that is challenged by many (most?) sociologists. The economists would usually respond thus: certainly, choices are constrained, and the economic consumer choice theory can embody more and more subtle constraints if need be. But in most economic models of consumption there have to be some degrees of freedom: the consumer still has to have some - even if not very much - discretion.

The second reason is that revealed preference, like other methods of indirect inference, tries to make inferences about one magnitude by inference from the pattern of correlation among other magnitudes. Even if this is technically possible, it can - as a practical matter - be very difficult to disentangle the different effects of multiple influences on consumption.

The third reason is perhaps the most serious of all. To use revealed preference, it is necessary to assume that the preference function to be revealed is the same for all the data used in its estimation. But if the data come from different years, or represent the aggregate behaviour of an aggregate whose composition changes from one data point to the next, then this is a strong assumption. Moreover it has had the unfortunate effect (unfortunate, at least, in the opinion of this author) of focusing attention on fixed consumer tastes and away from the reasons why tastes may change. Indeed, it was really only in the 1950s and 1960s, notably with the work of Becker and others, that the endogeneity of tastes came back on to the mainstream economic agenda - and then, essentially, only in theoretical work, and much less so in empirical work.

The consumer of mainstream economic theory, as described here, is an unexciting individual. He or she is an asocial hermit of fixed tastes. His or her behaviour is not, apparently, influenced by others. He or she has no need to experiment but, given the same products, prices and income, would continue to consume in the same way indefinitely. In that sense he or she has little need of variety, though the standard assumption of convexity in consumer theory will tend to mean that the consumer consumes a collection of different goods, and does not just consume one good to the exclusion of all others. In short, he or she is probably not very exciting company. However, not all the consumers that populate the economist's world are quite this dull - as we shall see!

\section{The giants}

So far, the reader may be forgiven for thinking, 'But there is no more to the economics of consumption than (almost unconstrained) utility maximisation.' But this reflects the deliberate choice to start with a hard core of mainstream economic theory (as it evolved between about 1930 and 1980). This has to be placed in the broader history of economic thought. When that has been done, it will become clear that the picture is much more interesting. 
We start in this section with some of the pioneers of political economy, from Smith (1776) - the 'giants' of our subject. ${ }^{5}$ Although Smith is widely thought of as one of the founder of free-market economics, his consumers are capable of greater flamboyance than the consumer of the last section. Indeed, Smith was well aware of some of the interdependences in demand, in a passage anticipating Veblen's (1899) concept of conspicuous consumption:

With the greater part of rich people, the chief enjoyment of riches consists in the parade of riches, which in their eye is never so complete as when they appear to possess those decisive marks of opulence which nobody can possess but themselves. (Smith, 1776, Book 1, chapter 11, part 2, p. 277)

Senior (1863), an influential classical economist, and first holder of the Drummond Chair of Political Economy at Oxford, recognised two important features of the consumer. First: 'Strong as is the desire for variety, it is weak compared with the demand for distinction, a feeling which ... may be pronounced to be the most powerful of human passions.' ${ }^{6}$

Distinction, of course, has become a central focus in some of the modern sociological analyses of consumption (Bourdieu, 1984). Senior also drew attention to 'The desire to build, to ornament and to furnish - tastes which, where they exist, are absolutely insatiable and seem to increase with every improvement in civilisation'?

It may seem to stretch the boundaries of economics to include the work of John Ruskin. But Ruskin himself considered his 'economical essays', Unto this Last, the best things he had ever written, and some of his followers classed him firmly as a political economist. As Geddes (1884) puts it, Ruskin believed that the good consumer has ' $[\mathrm{A}]$ primary duty of regulating expenditure with studied reference to its effect on the mind and body of the labourer, so at once seeking the minimum service from the lower occupations, and maximising that from the higher ones' (Geddes, 1884, p. 37).

Thus the desirability of a particular good for consumption cannot be detached from the means of production, a perspective in interesting contrast to Marx's (1859) observation 'We cannot say from the taste of the wheat whether it was raised by Russian serf, French smallholder or English capitalist.'

And it is of course quite justified to include Veblen, and his concept of conspicuous consumption, within this group of pioneering economists of consumption. For, although his contribution to sociology has exceeded his contribution to economics, at the time he wrote The Theory of the Leisure Class (1899) Veblen was the first editor of the Journal of Political Economy. This journal, edited at the University of Chicago, is one of the very most influential and mainstream of economics journals, and its editor is by definition an economist!

In view of these illustrious and imaginative origins, it may be puzzling why economics found itself going along the track described in section one. An important part of the answer is the immensely influential contribution of Alfred Marshall on the development of economics. ${ }^{8}$ There is an inherent 
tension in Marshall's book. For, while he took pains to describe some subtle and rich consumer behaviour, he felt it was imperative that economics should develop a rigorous theory of consumer behaviour, and to do that he had to start with the simplest case.

The early discussion in his Principles of Economics (Book III, chapter II) is tantalising. Marshall describes a consumer with some of the behavioural traits recognised in much more recent work on consumption. An important characteristic of Marshall's consumer is that the way in which he achieves higher 'utility' may change significantly as the target rises. Marshall recognised this in an important passage about the consumer:

Every step in his progress upwards increases the variety of his needs together with the variety in his methods of satisfying them. He desires not merely larger quantities of the things he has been accustomed to consume, but better qualities of those things; he desires a greater choice of things, and things that will satisfy new wants growing up in him. (Marshall, 1920, Book III, chapter II, section 1, para. 1)

Marshall's consumer becomes more subtle and varied in his consumption: 'As ... Man rises in civilisation, as his mind becomes developed ... his wants become rapidly more subtle and more various; and in the minor details of life he begins to desire change for the sake of change' (Marshall, 1920, III, II, 1, 2).

This is not simply an emergent demand for variety: Marshall's consumer becomes more social and conspicuous. Marshall is struck by the quotation from Senior, listed above. Despite this, Marshall's consumer is selective in those areas in which he seeks distinction. What starts as a demand to enable Marshall's consumer to take part in some 'higher activities' may in due course turn into a demand for more conspicuous purposes. Moreover, Marshall's consumer will not be satisfied with distinction alone. In due course he aspires to excellence for its own sake, even in private consumption: 'For, indeed, the desire for excellence for its own sake is almost as wide in its ranges as the lower desire for distinction' (Marshall, 1920, III, II, 4, 2).

Marshall anticipates Galbraith (1958) in arguing that, when consumption progresses beyond its simplest forms, the wants of Marshall's consumer are driven by his activities, and not vice versa: 'Each new step upwards is to be regarded as the development of new activities giving rise to new wants rather than of new wants giving rise to new activities' (Marshall, 1920, III, II, 4, 3).

This observation has methodological as well as substantive implications. Marshall uses it to explain why a more sophisticated analysis of consumption - which is not possible in the Principles - calls for prior developments in the analysis of production: 'Much that is of chief interest in the science of wants is borrowed from the science of efforts and activities' (Marshall, 1920, III, II, 4, 5).

Economists see this as a remarkable observation, because it anticipates the development of modern consumer theory. As Deaton and Muellbauer (1980) show, the modern neoclassical theory of demand has a very close 
formal similarity to that of production. This similarity is further exploited in household production theory, developed by Becker (1991). In household production theory, the household manager(s) combine purchased goods and services together with household labour to provide services to members of the household. Becker's work on the family shows how this approach can be applied to a variety of household decisions, though his approach is not to everyone's taste.

Moreover, in quoting McCulloch's (1849) discussion of the progressive nature of mankind, Marshall comes closest to describing the consumer as an innovator:

The gratification of a want or a desire is merely a step to some new pursuit. In every stage of his progress he is destined to contrive and invent, to engage in new undertakings; and when these are accomplished to enter with fresh energy upon others. (Marshall, 1920, III, II, 4, 5, quoting from McCulloch, 1849, chapter II)

But having whetted our appetite by sketching this picture of the subtleties of consumer behaviour, Marshall then set it aside to concentrate on his rigorous economic analysis. In his own words, Marshall's treatment of demand in Principles of Economics was 'an elementary analysis of an almost purely formal kind' (Marshall, 1920, III, II, 4, 6). While Marshall perhaps thought that the rigorous analysis of this particular aspect of consumer behaviour might take no more than a few years, it did in fact take many people much longer than that. Whether this is a case of lock-in to an uninteresting special case, or an indication of the sheer difficulty of developing theory in even this simple case, is hard to say. But it was only really in the 1970 s that economics started in earnest to move back to (what economists would consider) rigorous analysis of some of the other facets of Marshall's behaviour.

One of the influences was the recognition in some of the macroeconomic studies of consumption ${ }^{9}$ that decent modelling of consumption required certain developments beyond core micro theory. Another was that some of the 'travellers' who had explored the development of theories of consumption in other social sciences had come home to the economics community, and their findings were starting to shake things up.

\section{The travellers}

A prophet is not without honour, but in his own country, and among his own kin, and in his own house. (Mark, 6:4)

Even some economists of distinction have spoken of a cool reception on their return from journeys to meet other social science disciplines. Scitovsky (1976), for example, explored what the psychology of human motivation could teach the economist about consumption behaviour. Drawing on Berlyne's (1960) research on motivation, he explored how psychological concepts of arousal, personality, the pursuit of novelty, comfort and pleasure can be harnessed to build a much more subtle economic understanding of 
consumer behaviour. In the preface to his book, Scitovsky (1976) describes how his early ideas met with a uniform wave of hostility from economists: 'I was taken aback at first by such an unbroken string of negative reactions, but then took comfort in its fitting in so well with one of the main points I make here: that man wants novelty but cannot take, and gets disturbed by, too much of it.'

The economists seemed to consider that it was not their business to probe into the determinants of consumer tastes. Instead, it was enough to assume that these existed and that the consumer made rational, maximising choices consistent with those tastes. The fruits of Scitovsky's travels are very interesting, and have led to a stream of research that could best be described as an economic psychology of consumer behaviour - see, for example, the discussions in Furnham and Lewis (1986) and Bianchi (1998).

Another influential 'traveller' was Galbraith. While he has been one of the most influential economists in the wider world, his work has not always been met with enthusiasm by his professional colleagues. But Galbraith has been a traveller to the real world, holding major US government positions and acting as Kennedy's ambassador to India. In The Affluent Society Galbraith (1958, pp. 152-3) takes a very sceptical view of the preoccupation with productivity growth: 'As a society becomes increasingly affluent, wants are increasingly created by the process by which they are satisfied.'

Galbraith calls this a dependence effect, and notes that if production creates the wants it seeks to satisfy then it is unclear that welfare is higher at a greater level of production: it could just be the same. Galbraith notes that the businessman and lay reader may be puzzled over his continual emphasis on what may, to them, seem an obvious point. But it does not sit easily with the notion of fixed tastes, and the role of economic growth in satisfying such fixed tastes.

Lewis (1955), one of the great development economists, could also be described as a 'traveller'. He brought back to economics a deeper and richer understanding of the role of consumption in different societies. It is interesting that development economics has perhaps been the area of economics most closely connected with the work of other disciplines, notably anthropology. And, finally, Earl (1986, 1988a, b) provides a compelling account of lifestyle economics, gathered by working at the interface of economics and marketing.

It is interesting to find that some travellers from outside economics have been treated with reverence within the economics community. As noted above, Mary Douglas has left an important legacy in economic thought on consumption, and has written of how positively she felt about these travels (in Douglas and Isherwood, 1980).

\section{The revival}

The previous section was about the contributions made by travellers who on their return have remained outside the mainstream of economic analysis of 
consumption. This section picks up some of the subsequent contributions in this vein from authors who are still essentially part of the mainstream. What follows is no more than a small and rather idiosyncratic selection drawing heavily on earlier (joint) surveys by this author: Cowan et al. $(1997,1998)$, Swann (1999).

The papers collected in Becker (1996) show how far one of the leading economists in this field has moved beyond the narrow modern mainstream of section one. Half his papers in that collection are concerned with personal consumption capital, or routine and habit; the rest are concerned with social capital, or consumption as a social activity. The former describe a theory of rational addiction, and an analysis of the effect of price on consumption when there is rational addiction. The latter provide an economic theory of social interactions, of social influences on price, and of how social norms shape preferences.

Cowan et al. $(1997,1998)$ in the same way organise the recent literature into two parts: the effects of a consumer's own consumption history on his or her current consumption; and the effects of the consumption patterns of peers and rivals. This mirrors the distinction made by Becker (1996) between the roles of personal capital and social capital in shaping tastes in consumption.

\section{The consumer's past consumption history}

The central idea here is the obvious one that a consumer's history can create inertia in consumption patterns. One of the post-war pioneers, Duesenberry (1949), recognised that when incomes fall, families don't necessarily cut consumption right away, but run savings down to maintain the standard of consumption to which they have become accustomed. This basic observation has been variously interpreted as inertia or habit formation.

Brown (1952) modelled habit formation in demand behaviour as a positive autoregressive component in a traditional demand model. Friedman's (1957) concept of permanent income can also be seen in this tradition. Several of the more important subsequent contributions on the endogeneity of preferences have taken a similar perspective: for example, Becker and Murphy (1988), Donckner and Feichtinger (1993), Feichtinger et al. (1995), Gorman (1967), Gintis (1974), Pollak (1970), Weizacker (1971).

By contrast, some areas of economic theory explicitly recognise the individual consumer's demand for variety (for example, Dasgupta and Stiglitz, 1980). While the origin of the demand for diversity is not developed in detail, it has sometimes been interpreted in the current context as a desire on the part of the consumer to differentiate her current consumption pattern from her past.

Finally, the papers in Bianchi (1998) explore the active consumer: this is really the counterpart in consumption to the innovator in production. The active consumer does not rely on the producer to create new products and services to satisfy his or her desire for variety and novelty. Rather, the active consumer plays an important part in creating his or her own innovations, 
whether by 'journeys into the unknown' or by creating valuable collections from items of low individual value.

Most of the literature in this tradition has focused on microeconomic results, with less concern on detailed macroeconomic consequences (and especially dynamic consequences), that follow from them.

\section{Consumption patterns of peers and rivals}

The consumer of mainstream theory was an asocial hermit. Such an individual doesn't really need to signal to others. But not all economic thinking has seen the consumer that way. Veblen's (1899) theory of conspicuous consumption saw consumption as an activity undertaken to transmit a signal rather than simply to satisfy needs. Conspicuous consumption requires that individuals indulge in consumption activities recognised by their peers. But it also requires that they distinguish their consumption from that of ordinary people. And, indeed, it is not enough that consumption simply imitates that of the peer group: there must be imitation and innovation, so that the individual occupies a distinct place in the group. Several more recent contributions have re-examined this basic idea: Liebenstein (1950), Mason (1981), Earl (1986), Bagwell and Bernheim (1996) and Ireland (1994).

Kirman (1997) and Durlauf (1997) have reviewed recent economic literature on direct interaction between different economic 'agents'. Much of the literature is not focused exclusively on consumption as such, but is broader and more abstract in conception. But the same basic ideas surface, namely that non-market interactions can affect the utilities (or productivities) of 'agents'. Some important contributions are by Durlauf (1993), Kirman (1993), An and Kiefer (1995), Cowan and Cowan (1998) and Cowan et al. (1998).

A recent strand in the economics literature on conformity and conventions has revisited the phenomenon of 'fad' behaviour - Banerjee (1992), Bernheim (1994), Corneo and Jeanne (1999), Young (1993). ${ }^{10}$ Other contributions to the economic analysis of fashion cycles include Bikhchandani et al. (1992), Coelho and McClure (1993) and Pesendorfer (1995). Much of this work, admittedly, has focused essentially on equilibria, and has much less to say about dynamics. Much of the literature, moreover, focuses on information contagion: fads and imitation take place because private information is considered inadequate for decision making. Cowan et al. (1998) move beyond this by studying situations in which surges and waves in behaviour arise even if all consumers have good information about the properties of the good.

The literature on de facto standards makes a very explicit recognition of how one consumer's choice depends on the past and expected future choices of others - see Arthur (1989), David (1985), Farrell and Saloner (1985), Cowan (1991). The concept of network externalities (Katz and Shapiro, 1985 ) is of central importance in this context. As Farrell and Saloner put it, standards emerge because there are economies of scale in joint consumption. This was also recognised by Gaertner (1974). But in general this literature has a very simple concept of externality: the externality is positive, and 
applies equally to all members of the economy. Put another way, there are only (positive) peer effects, and every agent is the peer of every other. Two papers that advance beyond this simple assumption are Cowan and Cowan (1998) and David et al. (1998). Akerlof (1997) has made an unusual and very welcome attempt to link ethnographic studies and interpretations of peer effects with some of these theories.

This is no more than a selection. Indeed, a scan of many of the major journals in mainstream economics in the last few years would show just how much energy has gone into developing an economic theory of the consumer that goes well beyond the hard core described in section two. Even if the casual observer restricts his or her attention to the absolute mainstream, it is simply no longer tenable to say that there is nothing more to the economics of consumption than utility maximisation.

\section{Conclusion: the future?}

The last section should convince the reader that, at the beginning of the new century, there is certainly more to the economics of consumption than utility maximisation. There always was, though it has to be conceded that the preoccupation with econometric methods and revealed preference until the 1980s meant that economics was slow to revisit some of the subtleties of Marshall's consumer. But thanks in some degree to the travellers, who visited other disciplines and brought back rather richer insights into consumer behaviour, the last ten to twenty years have seen a proliferation of studies that recognise the endogeneity of tastes, strong interdependence in consumption patterns, and the many constraints on consumption behaviour (private and social) which limit consumer choice.

Any wild guesses about the future of the economics of consumption would be unwise. However, let us venture one speculation. There is growing interest in some parts of economics in agent-based simulation modelling. That is, where each consumer's behaviour is modelled at an individual level, and a simulation model collects all these virtual consumers together and allows them to interact. This moves away from the representative consumer described above to recognise, and indeed to celebrate consumer diversity.

Farrell (1998) describes applications of agent-based modelling to a variety of consumer behaviour. One application is to modelling record-buying behaviour. The simulation model has some 50,000 imaginary fad-following record buyers inside it. The behaviour patterns of these virtual people are based on real data collected by a market research company from record shops and radio stations. More generally, Epstein and Axtell (1996) and Epstein et al. (1999) use agent-based models to study emergent economic behaviour.

One very exciting possibility arriving from outside economics is the scope to use virtual reality technologies to present 'lifelike' representations of the outputs from the agent-based simulations. Thus, for example, Thalmann and 
Thalmann (1999) have created a 'virtual reality' representation of crowd behaviour, where the behaviour of each individual in the crowd, and how $\mathrm{s} /$ he interacts with the others, is modelled separately. Ten years ago, simulation was unpopular in the mainstream of economics, though more widely used by evolutionary economists and in the economics of innovation. That is changing, and some exciting possibilities exist if economists can harness the potential of virtual reality and other visualisation technologies to illuminate their simulations.

\section{Acknowledgement}

This chapter reflects my work with Robin Cowan on 'new' models of consumption, but he is not responsible for any infelicities here. The word 'almost' is inserted in the title because, of course, completely unconstrained utility maximisation is meaningless.

\section{Notes}

1 The irony is intentional: aggregation is not a trivial matter. The aggregate of different consumer behaviours will look like the behaviour of a single representative consumer only under very strong assumptions. It seems more promising to seek to represent aggregate consumption by a set of representative consumers (Swann and Tavakoli, 1994).

2 Deaton (1988) gives a summary of other more recent work in this tradition.

3 Duesenberry (1960, p. 233), here quoted from Becker (1996, p. 17).

4 Indeed, they thought it essential that theory and applied work must progress in tandem, but from the 1950s and (especially) 1960s a major split appeared between theory and applied work.

5 The selection here has a rather European bias. Langlois (2001) also explores the important contribution of the American economist Wesley Mitchell, among others.

6 Here quoted from Marshall (1920, Book III, chapter II, section 1, para. 4).

7 Here quoted from Jevons (1871, p. 103).

8 The discussion of Marshall draws on a more detailed article by the present author (Swann, 1999).

9 Notably Friedman (1957), Duesenberry (1949) and Liebenstein (1950).

10 This has something in common with the work of Granovetter and Soong (1986) from sociology and Miller et al. (1993) from marketing.

\section{References}

Akerlof, G. (1997), 'Social distance and social decisions', Econometrica, 65 (5), pp. 1005-27.

An, M., and Kiefer, N. (1995), 'Local externalities and societal adoption of technologies', Journal of Evolutionary Economics, 5, pp. 103-17.

Arthur, W. B. (1989), 'Competing technologies, increasing returns, and lock-in by historical events', Economic Journal, 99, pp. 116-31.

Bagwell, L. S., and Bernheim, B. D. (1996), 'Veblen effects in a theory of conspicuous consumption', American Economic Review, 86 (3), pp. 349-73. 
Banerjee, A. V. (1992), 'A simple model of herd behaviour', Quarterly Journal of Economics, 107, pp. 797-817.

Becker, G. S. (1991), A Treatise on the Family, enlarged edition, Cambridge MA and London, Harvard University Press.

Becker, G. S. (1996), Accounting for Tastes, Cambridge MA, Harvard University Press.

Becker, G. S., and Murphy, K. M. (1988), 'A theory of rational addiction', Journal of Political Economy, 96, pp. 675-700.

Berlyne, D. E. (1960), Conflict, Arousal and Curiosity, New York, McGraw-Hill.

Bernheim, D. (1994), 'A theory of conformity', Journal of Political Economy, 105, pp. 841-77.

Bianchi, M., ed. (1998), The Active Consumer, London, Routledge.

Bikhchandani, S., Hirschleifer, D., and Welch, I. (1992), 'A theory of fads, fashion, custom and cultural change as informational cascades', Journal of Political Economy, 100, pp. 992-1026.

Bourdieu, P. (1984), Distinction: a social critique of the judgement of taste, London, Routledge.

Brock, W., and Durlauf, S. (1995), Discrete Choice with Social Interactions, Madison WI, Department of Economics, University of Wisconsin.

Brown, T. M. (1952), 'Habit persistence and lags in consumer behaviour', Econometrica, 20, pp. 355-71.

Coelho, P. R. P., and McClure, J. E. (1993), 'Towards an economic theory of fashion', Economic Enquiry, 31, pp. 595-608.

Corneo, G., and Jeanne, O. (1999), 'Social organisation, status and savings behaviour', Journal of Public Economics, 70 (1), pp. 37-51.

Cowan, R. (1991), 'Tortoises and hares: choice among technologies of unknown merit', Economic Journal, 101, pp. 801-14.

Cowan, R., and Cowan, W. (1998), 'Quality differentials and the location of R\&D', Economics of Innovation and New Technology, 6 (2), pp. 201-29.

Cowan, R., Cowan, W., and Swann, G. M. P. (1997), 'A model of demand with interaction among consumers', International Journal of Industrial Organisation, 15, pp. 711-32.

Cowan, R., Cowan, W. and Swann, G. M. P. (1998), 'Waves in Consumption with Interdependence among Consumers', MERIT Working Paper 2/8-011, University of Maastricht.

Dasgupta, P., and Stiglitz, J. (1980), 'Uncertainty, industrial structure and the speed of R\&D', Bell Journal of Economics, 11, pp. 1-28.

David, P. A. (1985), 'Clio and the economics of QWERTY', American Economic Review, 75, pp. 332-6.

David, P. A., Foray, D., and Dalle, J. M. (1998), 'Marshallian externalities and the emergence and spatial stability of technological enclaves', Economics of Innovation and New Technology, 6 (2), pp. 147-82.

Deaton, A. S. (1988), 'Consumers' expenditure', in Eatwell, J., Millgate, M., and Newman, P. (eds), The New Palgrave: a dictionary of economics, London, Macmillan.

Deaton, A. S., and Muellbauer, J. (1980), Economic Theory and Consumer Behaviour, Cambridge, Cambridge University Press.

Donckner, E. J., and Feichtinger, G. (1993), 'Cyclical consumption patterns and rational addiction', American Economic Review, 83 (1), pp. 256-63.

Douglas, M., and Isherwood, B. (1980), The World of Goods: towards an anthropology of consumption, Harmondsworth, Penguin Books. 
Duesenberry, J. S. (1949), Income, Saving and the Theory of Consumer Behavior, Cambridge MA, Harvard University Press.

Duesenberry, J. S. (1960), 'Comment on an economic analysis of fertility', in Demographic and Economic Change in Developed Countries, Princeton NJ, Princeton University Press for the National Bureau of Economic Research.

Durlauf, S. N. (1993), 'Non-ergodic economic growth', Review of Economic Studies, 60, pp. 349-66.

Durlauf, S. N. (1994), 'Spillovers, stratification and inequality', European Economic Review, 38 (3), pp. 836-45.

Durlauf, S. N. (1997), 'Statistical mechanics approaches to socioeconomic behaviour', in Arthur, W. B., Durlauf, S. N., and Lane, D. (eds), The Economy as a Complex Evolving System II, Redwood City CA, Addison-Wesley.

Earl, P. E. (1986), Lifestyle Economics: consumer behaviour in a turbulent world, Brighton, Wheatsheaf.

Earl, P. E., ed. (1988a), Psychological Economics: development, tensions, prospects, Boston MA, Kluwer.

Earl, P. E., ed. (1988b), Behavioural Economics, Aldershot, Elgar.

Epstein, J. M., and Axtell, R. L. (1996), Growing Artificial Societies: social science from the bottom up, Cambridge MA, MIT Press for the Brookings Institution.

Epstein, J. M., Axtell, R. L., and Young, P. (1999), 'The emergence of economic classes in an agent-based bargaining model', in Durlauf, S., and Young, P. (eds), Social Dynamics, New York, Oxford University Press for the Santa Fe Institution.

Farrell, J. R., and Saloner, G. (1985), 'Standardization, compatibility and innovation', Rand Journal of Economics, 16, pp. 70-82.

Farrell, W. (1998), How Hits Happen: forecasting predictability in a chaotic marketplace, New York, Harper.

Feichtinger, G., Prskewetz, A., Herold, W., and Zinner, P. (1995), 'Habit formation with threshold adjustment: addiction may imply complex dynamics', Journal of Evolutionary Economics, 5, pp. 157-72.

Friedman, M. (1957), A Theory of the Consumption Function, Princeton NJ, Princeton University Press.

Furnham, A., and Lewis, A. (1986), The Economic Mind: the social psychology of economic behaviour, Brighton, Wheatsheaf.

Gaertner, W. (1974), 'A dynamic model of interdependent consumer behaviour', Zeitschrift für Nationalökonomie, 34, pp. 327-44.

Galbraith, J. K. (1958), The Affluent Society, Boston MA, Houghton Mifflin.

Geddes, P. (1884), John Ruskin, Economist, Edinburgh, Brown.

Gintis, H. (1974), 'Welfare criteria with endogenous preferences: the economics of education', International Economic Review, 15, pp. 415-30.

Gorman, W. M. (1967), 'Tastes, habit and choices', International Economic Review, 8, pp. 218-22.

Gorman, W. M. (1976), 'Tricks with utility functions', in Artis, M., and Nobay, A. R. (eds), Essays in Economic Analysis, Cambridge, Cambridge University Press.

Granovetter, M., and Soong, R. (1986), 'Threshold models of interpersonal effects in consumer demand', Journal of Economic Behaviour and Organization, 7 (1), pp. 83-100.

Houthakker, H. S., and Taylor, L. D. (1970), Consumer Demand in the United States: analysis and projections, second edition, Cambridge MA, Harvard University Press. 
Ireland, N. (1994), 'On limiting the market for status signals', Journal of Public Economics, 53, pp. 91-110.

Jevons, W. S. (1871), The Theory of Political Economy, ed. Collinson Black, R. D., Harmondsworth, Penguin Books (1970).

Katz, M., and Shapiro, C. (1985), 'Network externalities, competition, and compatibility', American Economic Review, 75, pp. 424-40.

Keynes, J. M. (1939), 'Professor Tinbergen's method', Economic Journal, 49, pp. 558-68.

Kirman, A. (1993), 'Ants, rationality and recruitment', Quarterly Journal of Economics, 108, pp. 137-56.

Kirman, A. (1997), 'Economics with interacting agents', in Arthur, W. B., Durlauf, S. N., and Lane, D. (eds), The Economy as a Complex Evolving System II, Redwood City CA, Addison-Wesley.

Langlois, R. (2001), 'Knowledge, consumption, and endogenous growth', Journal of Evolutionary Economics, 11 (1), pp. 77-93.

Lewis, W. A. (1955), The Theory of Economic Growth, London, Allen \& Unwin.

Liebenstein, H. (1950), 'Bandwagon, snob and Veblen effects in the theory of consumers' demand', Quarterly Journal of Economics, 65, pp. 183-207.

Marshall, A. (1920), Principles of Economics, eighth edition, London, Macmillan.

Marx, K. (1859), Critique of Political Economy, London, Lawrence \& Wishart (1983).

Mason, R. S. (1981), Conspicuous Consumption: a study of exceptional consumer behaviour, Aldershot, Gower.

McCulloch, J. R. (1849), The Principles of Political Economy, reprinted as Vol. II of The Collected Works of J. R. McCulloch, ed. O'Brien, D. P. (1995), London, Routledge.

Miller, C. M., McIntyre, S. M., and Mantrala, M. K. (1993), 'Towards formalising fashion theory', Journal of Marketing Research, 30, pp. 142-51.

Pesendorfer, W. (1995), 'Design innovation and fashion cycles', American Economic Review, 85, pp. 771-92.

Pollak, R. A. (1970), 'Habit formation and dynamic demand functions', Journal of Political Economy, 78, pp. 60-78.

Popper, K. (1957), The Poverty of Historicism, London, Routledge.

Scitovsky, T. (1976), The Joyless Economy: an enquiry into human satisfaction and consumer dissatisfaction, London, Oxford University Press.

Senior, N. (1863), Outline of the Science of Political Economy, fifth edition, London, Griffin.

Smith, A. (1776), The Wealth of Nations, ed. Skinner, A., Harmondsworth, Penguin Books (1974).

Stone, J. R. N. (1954), The Measurement of Consumers' Expenditure and Behaviour in the United Kingdom, 1920-38, Cambridge: Cambridge University Press.

Swann, G. M. P. (1989), 'Ragnar Frisch', in Katz, B. (ed.), The Nobel Laureates in Economics, New York, Garland.

Swann, G. M. P. (1999), 'Marshall's consumer as an innovator', in Essays in Honour of Brian Loasby, Cheltenham, Elgar.

Swann, G. M. P., and Tavakoli, M. (1994), 'An econometric analysis of television viewing, and the welfare economics of introducing an additional channel in the UK', Information Economics and Policy, 6, pp. 25-51.

Thalmann, N. M., and Thalmann, D. (1999), 'Avatars and Autonomous Virtual 
Humans in Virtual Environments', IEEE Virtual Reality conference, Houston TX, 13-17 March.

Veblen, T. (1899), The Theory of the Leisure Class: an economic study of institutions, New York, Macmillan.

Weizäcker, C. C. von (1971), 'Notes on endogenous changes of taste', Journal of Economic Theory, 3, pp. 345-72.

Young, P. (1993), 'The evolution of conventions', Econometrica, 61, pp. 57-84. 